\title{
Pharmacogenomic markers of glucocorticoid response in the initial phase of remission induction therapy in childhood acute lymphoblastic leukemia
}

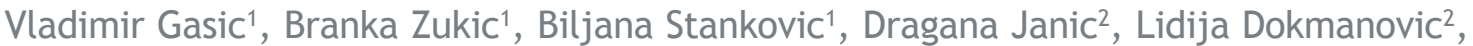 \\ Jelena Lazic ${ }^{2}$, Nada Krstovski², Vita Dolzan³ ${ }^{3}$ Janez Jazbec ${ }^{4}$, Sonja Pavlovic ${ }^{1}$, Nikola Kotur ${ }^{1}$ \\ ${ }^{1}$ Laboratory for Molecular Biomedicine, Institute of Molecular Genetics and Genetic Engineering, University of Belgrade, \\ Belgrade, Serbia \\ 2 Department of Hematology and Oncology, University Children's Hospital, University of Belgrade, Belgrade, Serbia \\ ${ }^{3}$ Pharmacogenetics Laboratory, Institute of Biochemistry, Faculty of Medicine, University of Ljubljana, Ljubljana, Slovenia \\ ${ }^{4}$ Department of Oncology and Haematology, University Children's Hospital, University Medical Centre Ljubljana, Ljubljana, \\ Slovenia
}

Radiol Oncol 2018; 52(3): 296-306.

Received 19 February 2018

Accepted 24 April 2018

Correspondence to: Nikola Kotur, Ph.D., Institute of Molecular Genetics and Genetic Engineering, University of Belgrade, Vojvode Stepe 444a, 11010 Belgrade, Serbia. Phone: +381 113976 445; Fax: +381 113975 808; E-mail: nikola.kotur@imgge.bg.ac.rs

Disclosure: No potential conflict of interest were disclosed.

Background. Response to glucocorticoid (GC) monotherapy in the initial phase of remission induction treatment in childhood acute lymphoblastic leukemia (ALL) represents important biomarker of prognosis and outcome. We aimed to study variants in several pharmacogenes (NR3C1, GSTs and ABCBI) that could contribute to improvement of GC response through personalization of GC therapy.

Methods. Retrospective study enrolling 122 ALL patients was carried out to analyze variants of NR3C 1 (rs33389, rs33388 and rs6198), GST1 (null genotype), GSTMl (null genotype), GSTPI (rs1695 and rs1 138272) and ABCB1 (rs1 128503, rs2032582 and rs1045642) genes using PCR-based methodology. The marker of GC response was blast count per microliter of peripheral blood on treatment day 8. We carried out analysis in which cut-off value for $\mathrm{GC}$ response was 1000 (according to Berlin-Frankfurt-Munster [BFM] protocol), as well as 100 or 0 blasts per microliter.

Results. Carriers of rare NR3C1 rs6198 GG genotype were more likely to have blast count over 1000, than the noncarriers ( $p=0.030$ ). NR3C1 CAA (rs33389-rs33388-rs6198) haplotype was associated with blast number below 1000 $(p=0.030)$. GSTPI GC haplotype carriers were more likely to have blast number below $1000(p=0.036)$, below 100 $(p=0.028)$ and to be blast negative $(p=0.054)$, while GSTPI GT haplotype and rs 1138272 T allele carriers were more likely to be blasts positive ( $p=0.034$ and $p=0.024$, respectively). ABCB1 CGT (rs 1 128503-rs2032582-rs 1045642) haplotype carriers were more likely to be blast positive ( $p=0.018)$.

Conclusions. Our results have shown that NR3C 1 rs6198 variant and GSTP1 rs 1695-rs1 138272 haplotype are the most promising pharmacogenomic markers of GC response in ALL patients.

Key words: pharmacogenomics; childhood ALL; glucocorticoids; glucocorticoid receptor gene; glutathione S-transferase genes; multidrug resistance 1 gene

\section{Introduction}

Acute lymphoblastic leukemia (ALL) is the most common hematological and overall malignancy in pediatrics, accounting for around $30 \%$ of all childhood cancers and around $80 \%$ of all childhood leukemias. It is one of the pediatric malignancies with the highest cure rate, exceeding $80 \%$, when treated 
with standardized protocols like the European standard, the Berlin-Frankfurt-Munster (BFM) protocol. ${ }^{1-3}$ However, there is still more than $10 \%$ of patients with unfavorable outcome. The treatment of childhood ALL is based on risk stratification. Patients can be classified into groups according to the features that have been shown to affect prognosis and risk of treatment failure. In time, more elements are considered in order to modulate the treatment protocols and make them more efficient. Implementation of pharmacogenomics in the childhood ALL therapeutic strategy is the most promising approach to improve the outcome of childhood ALL. ${ }^{4}$

The four main components of ALL therapy are remission induction, consolidation, maintenance, and central nervous system-directed therapy. According to the BFM protocol, in the initial phase of the remission induction treatment of childhood ALL, glucocorticoid (GC) monotherapy is administered during the first 8 days. Its goal is to lower the number of lymphoblasts since GC have the ability to induce apoptosis in leukemic cells mediated through the glucocorticoid receptor (GR). ${ }^{5}$ The lymphoblast count on the day 8 is one of the stratification criteria important for therapy regime and survival. ${ }^{6}$ If the blast count in blood is below 1000/ microL, the patient is declared as a GC sensitive patient or a prednisone good responder (PGR). If the peripheral blast count of a patient remains over $1000 /$ microL, the patient is declared as GC resistant patient or a prednisone poor responder (PPR) and this is associated with a poor prognosis.

The mechanism of GC resistance in childhood ALL is still poorly understood, but genetic factors might play an important role.-9 Therefore, it is of great importance for better treatment of childhood ALL to investigate, understand and overcome the problems related to pharmacogenomics profile of patients with a poor response to the initial GC treatment.

The glucocorticoid receptor gene (NR3C1) codes the GR, which is essential for the effects of glucocorticoids to manifest. Several NR3C1 variants, leading to altered sensibility of GR to glucocorticoids have been studied in pediatric diseases. Most frequently studied variants, like rs6189/rs6190 (ER22/23EK) and rs56149945 (N363S) have not shown significant association with the response on the day 8 , when it comes to the therapeutic response to glucocorticoids in ALL. ${ }^{10,11}$ One extensively studied variant, rs41423247 (BclI polymorphism), has shown association with the therapeutic response. ${ }^{12}$
Three variants in the NR3C1 gene, rs33389 (c.1185-6766C $>\mathrm{T}$ ), $\quad \mathrm{rs} 33388$ (c.1185-3562A $>\mathrm{T}$ ) and rs6198 (c. ${ }^{* 3833 A>G}$ ) have not been widely studied as pharmacogenomics markers in childhood ALL. The first two variants are located in intron 2, where they can alter consensus recognition sites for RNA splicing factors. ${ }^{13}$ If the minor rs33389 $\mathrm{T}$ allele and the major rs33388 A allele are present, alternate splicing occurs and an isoform of GR with lower affinity for glucocorticoids is expressed in a higher degree. ${ }^{14}$ In the pediatric nephrotic syndrome, the steroid response was affected by the presence of these two alleles in intron $2 .{ }^{15}$ The rs6198 variant is located in the 3' UTR region exon $9 \beta$, in the "ATTTA" motif of an isoform of GR with drastically lower affinity for glucocorticoids. ${ }^{16}$ If the minor rs6198 G allele is present, the mRNA becomes more stable and it leads up to greater translation of the isoform of GR with lower affinity for glucocorticoids. ${ }^{17}$

Three glutathione S-transferase (GST) genes (GSTP1, GSTT1, and GSTM1) code the GST proteins, which are essential for GC elimination by making its first step, conjugation, possible. ${ }^{18,19}$ Nullallele variants of GSTM1 and GSTT1 caused by a deletion of the gene, result in the absence of activity of these enzymes. Additionally, it was reported that GSTP1 gene variants rs1695 (c.313A>G, p.Ile105Val) and rs1138272 (c.341C >T, p.Ala114Val) influence the activity and the structure of GSTP1 and alter the efficiency of GC conjugation, if the minor alleles are present..$^{20} \mathrm{An}$ association between the rs 1695 variant and GC response was found in ALL. ${ }^{21}$

The multidrug resistance 1 gene (MDR1, also known as $A B C B 1$ ), encodes for a membrane transporter P-glycoprotein (P-gp), responsible for the efflux of chemotherapeutic agents used in leukemia therapy.22 Glucocorticoids are substrates of P-gp, which transports glucocorticoids out of cells. Overexpression of P-gp could mediate GC resistance. ${ }^{23}$ When considering $A B C B 1$, three variants were often analyzed as pharmacogenomics markers for GC response (rs1128503 (c.1236C >T, p.Gly412=), rs2032582 (c.2677G>A/T, p.Ser893Ala) and rs1045642 (c.3435TC>T, p.Ile1145=)). The rs2032582 variant is a missense mutation, while rs1045642 is a synonymous mutation which leads to decreased expression of $A B C B 1$ gene on the intestinal cell membranes. ${ }^{24}$ It was found that the steroid response in children with nephrotic syndrome varied based on the expression of $A B C B 1$ gene..$^{25}$

There have been a few reports which dealt with the topic of pharmacogenomics of GC resistance 
in adult leukemias, but they lacked conclusive evidence of a single contributing mechanism. ${ }^{26}$ The topic of pharmacogenomics of GC resistance in ALL, when it comes to the pediatric population, has not been sufficiently studied. In the reported results, only tendencies towards association with GC response for certain genotypes ${ }^{27}$ have been found, while most of the genetic variants, shown to be relevant for GC response, have never been studied in childhood ALL.

The aim of this study is to investigate the association between variants in NR3C1, GSTP1, GSTT1, GSTM1 and ABCB1 genes and GC therapeutic response in the initial phase of remission induction therapy of pediatric ALL patients. Also, we aimed to investigate if the analyzed pharmacogenomics markers could be helpful to achieve improved personalization of GC therapy, leading to more individualized approach. Namely, other values than 1000 of blast number on day 8 might be potentially used as a marker of therapy efficacy. For example, it has been reported that childhood ALL patients who has zero blasts on day 8 (blast negative), have longer disease-free survival than patients with detectable blasts (blast positive). ${ }^{28} \mathrm{In}$ order to better characterize GC response on day 8 related to analyzed genetic variants, we carried out additional analysis in which cut-off value for GC response was 100 or 0 blasts in peripheral blood. By understanding the factors which contribute to GC resistance or good response, predictions could be made for an individual patient before the initial treatment, in order to use the adequate treatment regime and increase the chances of more efficient GC response.

\section{Patients and methods}

\section{Patients}

Peripheral blood samples $(n=122)$ have been collected from unselected patients with the diagnosis of childhood ALL from the University Children's Hospital in Belgrade. The samples for genetic analyses were collected on the day of the diagnosis. Childhood ALL patients were diagnosed, stratified in risk groups and treated according to BerlinFrankfurt-Munster protocols: BFM ALL IC-2002 and BFM ALL IC-2009. All patients received induction therapy with prednisone. This study was approved by the Ethics Committee of the University Children's Hospital, University of Belgrade. The study was conducted according to the principles of Declaration of Helsinki.

\section{DNA isolation}

Genomic DNA was extracted from peripheral blood samples of the participants' using a QIAamp DNA Blood Mini Kit (Qiagen, Hilden, Germany) and stored at $-20{ }^{\circ} \mathrm{C}$ until analysis.

\section{GSTM1 and GSTT1 deletion detection}

The detection of GSTM1 and GSTT1 homozygous deletions was performed using multiplex polymerase chain reaction (PCR), as previously described with modifications. ${ }^{29}$ In the final reaction volume of 20 microL, $1 x$ buffer were added, $3.875 \mathrm{mM}$ of $\mathrm{MgCl}_{2}, 0.5 \mathrm{mM}$ of dNTP, 0.3 microM of the forward and reverse primer for GSTT1, 0.25 microM of the forward and the reverse primer for GSTM1, 0.25 microM of forward and reverse primer for $\beta$ globin gene segment (control PCR product), 1U of Taq polymerase (Hot Star polymerase, Qiagen, Hilden, Germany) and 60ng of DNA. After the initial denaturation at $95 \mathrm{C}$ for $15^{\prime}$, followed 35 cycles of $95^{\circ} \mathrm{C} /$ $53{ }^{\circ} \mathrm{C} / 72{ }^{\circ} \mathrm{C}$, lasting $30^{\prime \prime}, 45^{\prime \prime}$ and $60^{\prime \prime}$ respectively, ending with a final extension step at $72{ }^{\circ} \mathrm{C}$ lasting for $7^{\prime}$.

\section{Genotyping of $A B C B 1$ variants}

The variant rs2032582 of $A B C B 1$ gene was genotyped using the amplification-refractory mutation system polymerase chain reaction (ARMS PCR). A forward primer was designed for each allele specifically in order to pinpoint the exact genotype. The protocol was adapted from Kuzawski and coworkers. ${ }^{30}$ For each patient's sample, 3 separate PCR mixes were prepared, each containing different allele specific primer. In the final reaction volume of 15 microL, $1 x$ buffer were added, $3 \mathrm{mM}$ of $\mathrm{MgCl}_{2}$, $0.67 \mathrm{mM}$ of dNTP, 0.3 microM of the forward (allele specific) and reverse primer, $1 \mathrm{U}$ of Taq polymerase (Hot Star polymerase, Qiagen, Hilden, Germany) and $60 \mathrm{ng}$ of DNA. The PCR program started with a $95^{\circ} \mathrm{C}$ initial denaturation which lasted for $15^{\prime}$, followed by 10 cycles of $95^{\circ} \mathrm{C} / 60^{\circ} \mathrm{C} / 72^{\circ} \mathrm{C}$ lasting $30^{\prime \prime}, 30^{\prime \prime}$ and $40^{\prime \prime}$ respectively, followed by $30 \mathrm{cy}-$ cles of $95^{\circ} \mathrm{C} / 56^{\circ} \mathrm{C} / 72{ }^{\circ} \mathrm{C}$, lasting $30^{\prime \prime}, 30^{\prime \prime}$ and $40^{\prime \prime}$ respectively and the final step was an extension at $72{ }^{\circ} \mathrm{C}$ which endured for $5^{\prime}$.

Variants rs1045642 and rs1128503 of $A B C B 1$ were genotyped using the Kompetitive Allele Specific PCR genotyping system (KASP) (LGC, Teddington, Middlesex, UK), according to manufacturer's instructions. 


\section{Genotyping of NR3C1 variants}

Variants rs33389, rs33388 and rs6198 of NR3C1 were genotyped using TaqMan ${ }^{\circledR}$ SNP Genotyping Assays (Thermo Fisher Scientific) according to manufacturer's instructions. The fluorofore VIC was used to detect the wild type allele, while FAM was used to detect the variant allele. For genotyping of rs33389, rs33388 and rs6198 variants, C__1032036_10, C__1046426_10 and C__8951023_10 assays were used, respectively.

\section{Genotyping of GSTP1 variants}

Variants rs1695 and rs1138272 of GSTP1 were detected using the KASP genotyping system according to manufacturer's instructions (LGC, Teddington, Middlesex, UK).

\section{Statistical analysis}

Hardy-Weinberg equilibrium conformance was examined using $\chi^{2}$ test. Haplotype phases and frequencies were estimated using Arlequin software. ${ }^{31}$ The associations between carrier status of specific allele or haplotype and the number of blasts at the day 8 have been analyzed in $2 \times 2$ contingency tables using the $\chi^{2}$ test or the Fisher's exact test, when appropriate. Both dominant and recessive genetic model were applied when we considered single variant at the time, and stronger association with GC response was reported. Carriers of a specific haplotype were compared to all other patients with any other haplotype for each haplotype. Odds ratio with $95 \%$ confidence interval was used to assess the impact of clinical or genetic variable on GC drug response. The cut-off for statistical significance has been chosen at the value of $p=0.05$, while the cutoff value for borderline significance has been chosen at the value of $p=0.07$. To control for demographic and clinical difference between groups, multivariate analysis was performed using logistic regression. Correlation between continuous variables were estimated using Spearman's correlation coefficient (rs). The SPSS software package (IBM SPSS Statistics v.21) was used for statistical analyses.

\section{Results}

Demographic and clinical characteristics of childhood ALL patients on diagnosis

Out of 122 childhood ALL patients, there were 66 boys $(54.1 \%)$ and the median age was 5.2 (inter- quartile range: 3.3-10.2) years. B-cell leukemia was represented with $108(88.5 \%)$ cases and the rest of patients were diagnosed with T-cell leukemia. About $47 \%$ of patients had initially over 20,000 white blood cells (WBC) per microliter of blood, which is considered as unfavorable factor according to both BFM ALL IC-2002 and BFM ALL IC2009 protocols (Table 1 ).

\section{GC response on day 8}

In our study, blast count per microliter of blood on day 8 was used as surrogate marker of GC response. There were thirteen patients $(11 \%)$ with more than 1000 blasts/microL on day 8 of GC treatment in our cohort of patients. We have analyzed the correlation of clinical and demographic characteristics of patients with prednisone response. Namely, leukocyte count on diagnosis was positively correlated with absolute blast count on day 8 ( $r s=0.44$, $p=0.000001)$. In addition, patients suffering from T-cell leukemia were in greater risk to respond poorly to initiation GC treatment $(\geq 1000$ blasts/ microL on day 8) (Fisher's exact test, $\mathrm{p}=0.043$ ) than B-cell leukemia patients. Furthermore, age and gender of childhood ALL patients showed borderline association with prednisone response (Table 1).

\section{Association of gene variants with PGR and PPR according to BFM protocol}

Two homozygous deletions in GSTM1 and GSTP1 genes were studied as well as 8 single nucleotide variants (SNV) in NR3C1 (rs33389, rs33388 and rs6198), GSTP1 (rs1695 and rs1138272) and $A B C B 1$ (rs1128503, rs2032582 and rs1045642) genes. Genotype frequencies of all analyzed SNVs conformed to HW equilibrium for the ALL cohort.

When we carried out analysis in which 1000 blasts/microL set the limit of PGR and PPR, we found some positive correlation of pharmacogenomic markers with GC response. Regarding NR3C1 gene, our results have shown that NR3C1 variants were associated with glucocorticoid response on day 8. Namely, rare NR3C1 rs6198 GG genotype was associated with PPR (Fisher's exact test; $\mathrm{p}=0.030$ ) (Table 2). When estimated haplotypes of NR3C1 gene were considered, it was found that CAA (rs33389-rs33388-rs6198) haplotype was associated with PGR $(<1000$ blasts/microL) (Fisher's exact test; $\mathrm{p}=0.030$ ) (Table 3). Both associations remained significant or borderline significant when controlled for age, gender and ini- 
TABLE 1. Clinical and demografic characteristics and their association with glucocorticoid (GC) response. The GC response is assesed by absolute number of blasts per $\mathrm{mm} 3$ of blood on day 8 . Statistically significant associations $(p<0.05)$ were bolded

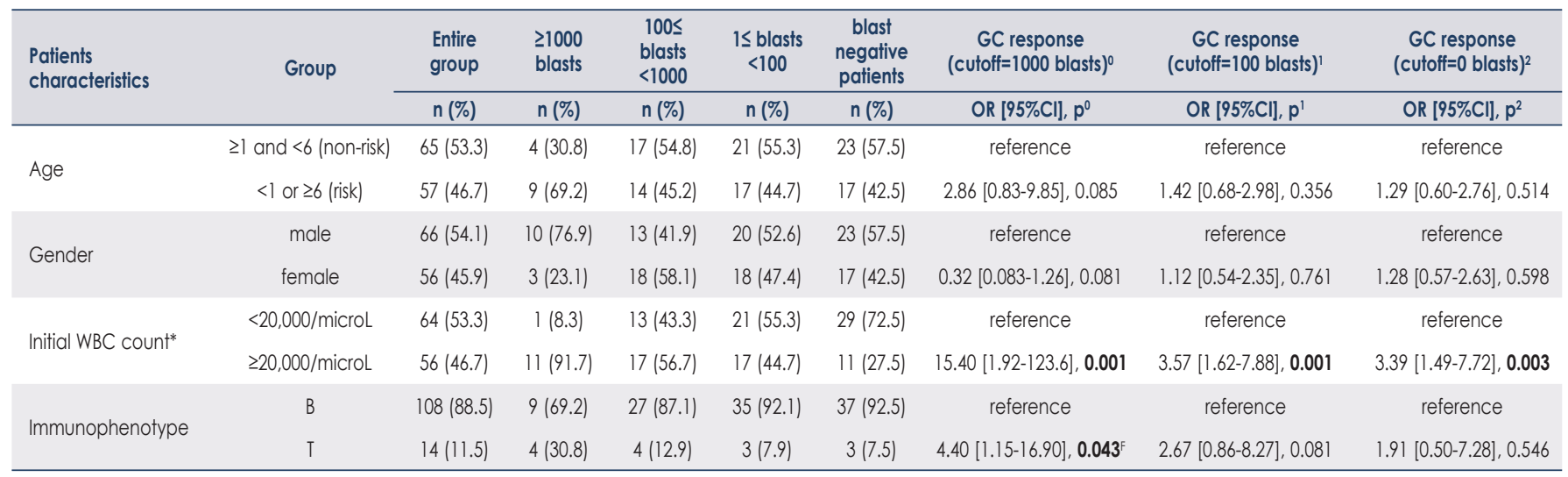

${ }^{0}$ Association with prednosine response on day 8 according to Berlin-Frankfurt-Munster (BFM) protocol: prednisone poor responder (PPR) group ( $\geq 1000$ blasts) vs. prednisone good responder (PGR) group (<1000 blasts)

Association with number of blasts on day 8 with cut-off value of 100: higher ( $\geq 100$ blasts) vs lower (< 100 blasts) number of blasts

Association with blast status on day 8: blast positive vs blast negative patients.

F Fisher exact test

OR = Odds ratio between a group with higher number of blasts in comparison with a group with lower number of blasts. The group with lower number of blasts represents reference group.

$\mathrm{Cl}=$ Confidence interval

tial WBC count (logistic regression, $\mathrm{p}=0.036$ and $\mathrm{p}=0.052$, respectively) (Tables 2 and 3 ).

When variants in $A B C B 1$ and GST genes were considered in relation to GC response, no significant association was found. However, when estimated haplotypes were considered, GSTP1 GC (rs1695-rs1138272) haplotype was associated with PGR ( $\chi^{2}$ test, $\left.\mathrm{p}=0.036\right)$ (Table 3$)$.

\section{Additional analyses of GC response on day 8 in regard to genetic variants}

Besides cut-off value of 1000 blasts/microL on day 8 , used to delimit patients with good or poor GC response according to BFM protocol, other values of blast count on day 8 might be potentially used as a marker of GC response. In order to confirm importance of analyzed genetic variants to GC response, we carried out additional analyses in which cut-off value for prednisone response was 0 (blast negative) or 100 blasts in peripheral blood. In our group of childhood ALL patients, 40 (32.8\%) were blast negative, while $38(31.1 \%)$ patients had between 1 and 99 blasts/microL after 8 days of GC treatment. Initial WBC count was correlated with blast positive status and higher number of blasts $(\geq$ 100 blasts/microL) (Table 1).

Regarding NR3C1 gene, our results have shown that carriers of minor rs33389 $\mathrm{T}$ allele tended towards higher blast count ( $\geq 100$ blasts/microL) $\left(\chi^{2}\right.$ test; $\mathrm{p}=0.095)$, while carriers of minor rs33388 T al- lele tended towards lower blast count $(<100$ blasts/ microL) $\left(\chi^{2}\right.$ test; $\left.p=0.098\right)$, but the results didn't reach statistical significance. When estimated haplotypes were considered, identical associations were obtained, because rs33389 $\mathrm{T}$ allele defines relatively rare TAA (rs33389-rs33388-rs6198) haplotype, while rs33388 $\mathrm{T}$ allele defines the most frequent CTA haplotype (Tables 2 and 3).

Additional analysis regarding GSTP1 gene showed that carriers of minor GSTP1 rs1138272 $\mathrm{T}$ allele were about 5 times more likely to be blast positive on day 8 , when compared to carriers of CC genotype ( $\chi^{2}$ test; $\left.p=0.024\right)$. Next, we analyzed estimated haplotypes of GSTP1 gene consisting of rs1695 and rs1138272 variants. We found that GSTP1 GC haplotype is associated not only with PGR, but also with lower blast count on day 8. Namely, this haplotype was associated with blast count below $100(<100$ blasts/microL, $\chi^{2}$ test; $\left.p=0.028\right)$ and borderline associated with blast negative status ( $\chi^{2}$ test; $p=0.054$ ). Also, it was shown that GSTP1 GT haplotype is borderline associated with higher blast count ( $\geq 100$ blasts/microL, $\chi^{2}$ test; $\left.p=0.062\right)$ and significantly associated with blast positive status ( $\chi^{2}$ test; $p=0.034$ ). The majority of those associations remained significant or borderline significant when controlled for age, gender and initial WBC count employing logistic regression. Taken together, our results regarding GSTP1 variants indicate that carriers of GC haplotype have better response to prednisone treat- 
TABLE 2. Genotype frequencies and association with glucocorticoid (GC) response. The GC response is assesed taking into account absolute number of blasts per mm3 of blood on day 8. For univariate analysis, chi square test was used, unless differently stated. Dominant model was used unless differently stated. Statistically significant associations $(p<0.05)$ were bolded

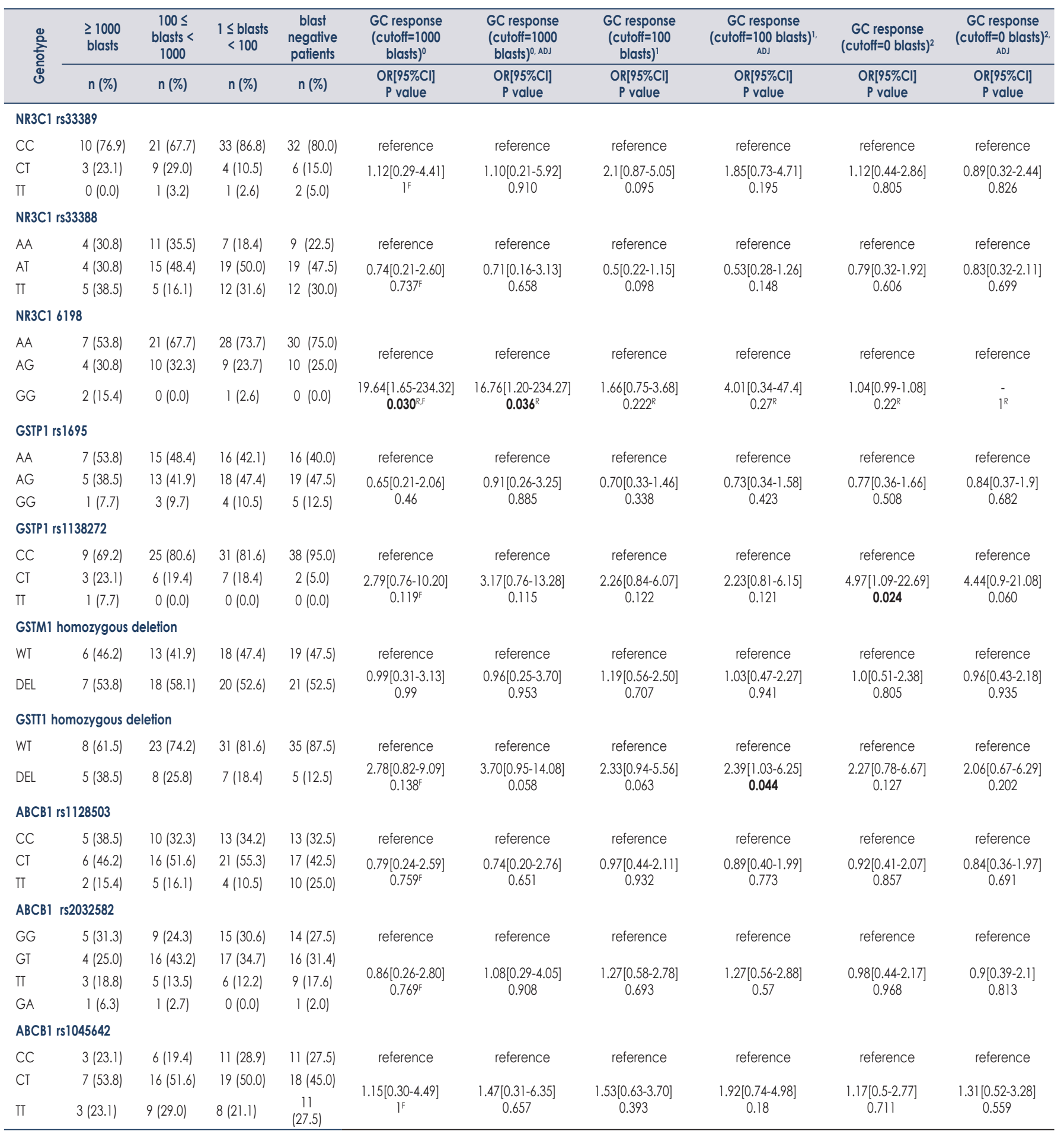

${ }^{0}$ Association with prednosine response on day 8 according to Berlin-Frankfurt-Munster (BFM) protocol: prednisone poor responder (PPR) group ( $\geq 1000$ blasts) vs. prednisone good responder (PGR) group (< 1000 blasts)

Association with number of blasts on day 8 with cut-off value of 100: higher ( $\geq 100$ blasts) vs lower (< 100 blasts) number of blasts

2 Association with blast status on day 8 : blast positive vs blast negative patients.

F Fisher exact test

R Recessive model

${ }^{A D J}$ Adjusted for age, gender and initial white blood cells (WBC) count using logistic regression

$\mathrm{OR}=$ Odds ratio between a group with higher number of blasts in comparison with a group with lower number of blasts. The group with lower number of blasts represents reference group.

$\mathrm{Cl}=$ Confidence interval 
TABELE 3. Haplotype carring status and association with glucocorticoid (GC) response. The GC response is assesed taking into account absolute number of blasts per mm3 of blood on day 8. For univariate analysis, chi square test was used, unless differently stated. Statistically significant associations ( $p<$ 0.05) were bolded

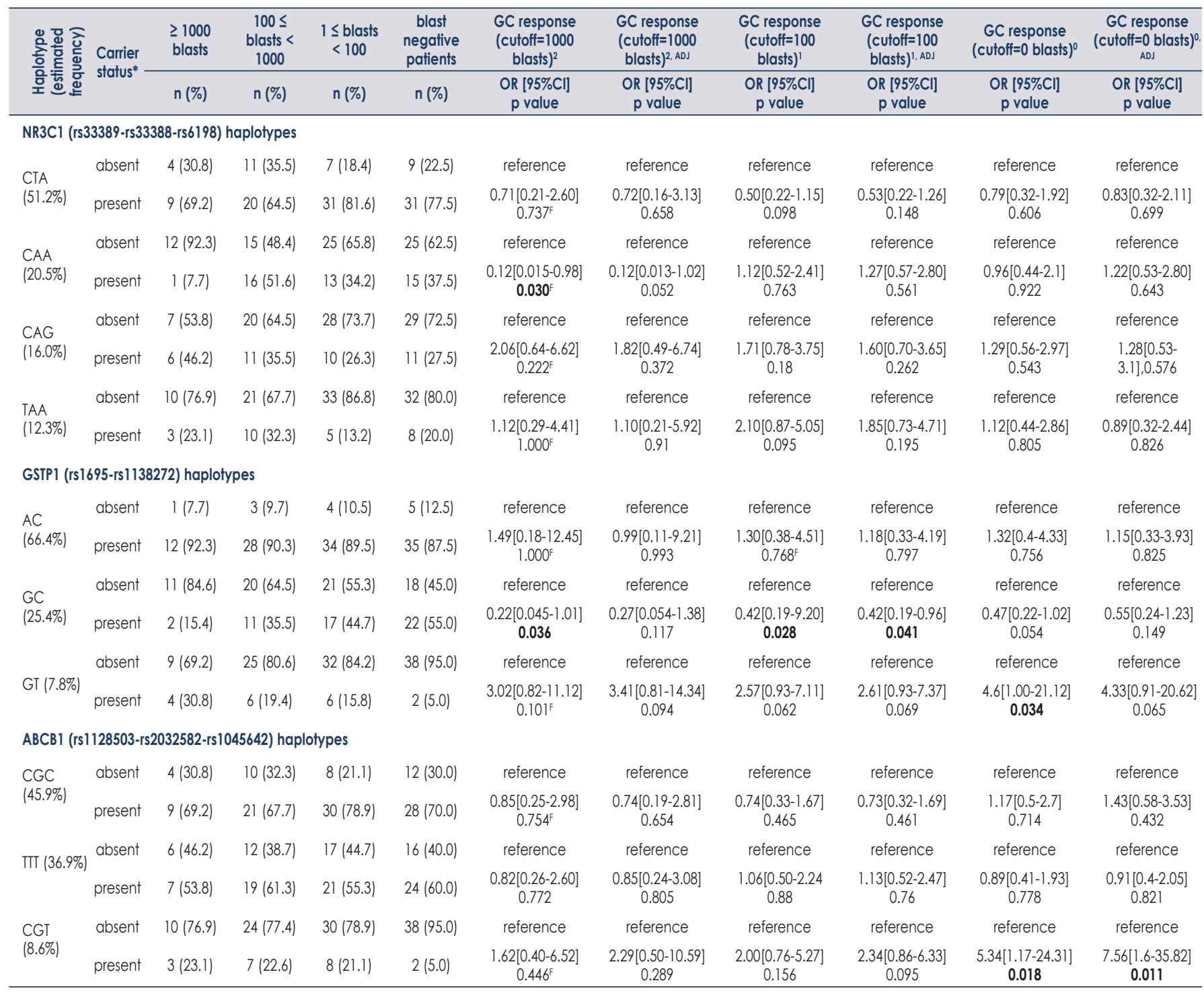

${ }^{0}$ Association with prednosine response on day 8 according to Berlin-Frankfurt-Munster (BFM) protocol: prednisone poor responder (PPR) group ( $\geq 1000$ blasts) vs. prednisone good responder (PGR) group (< 1000 blasts)

Association with number of blasts on day 8 with cut-off value of 100: higher ( $\geq 100$ blasts) vs lower (< 100 blasts) number of blasts

Association with blast status on day 8 : blast positive vs blast negative patients.

Fisher exact test

ADJ Adjusted for age, gender and initial white blood cells (WBC) count using logistic regression

$\mathrm{OR}=$ Odds ratio between a group with higher number of blasts in comparison with a group with lower number of blasts. The group with lower number of blasts represents reference group.

$\mathrm{Cl}=$ Confidence interval

ment, while carriers of GT haplotype have poorer response to prednisone treatment.

Regarding GSTT1 gene, our results have shown that carriers of null genotype are more likely to have blast count over 100 ( $\geq 100$ blasts/microL) ( $\chi^{2}$ test; $\mathrm{p}=0.063)$, in comparison with carriers of at least one functional GSTT1 gene copy. Interestingly, when controlled for age, gender and initial WBC count, this association turned out to be statistically significant (Logistic regression, $\mathrm{p}=0.044$ )

Regarding $A B C B 1$ gene variants in relation to blast count, no association was found. However, when estimated haplotypes were considered, it was found that carriers of relatively rare CGT (rs1128503-rs2032582-rs1045642) haplotype had been 5 times more likely to be blast positive $\left(\chi^{2}\right.$ 
test; $\mathrm{p}=0.018$ ), than the non-carriers. This association remained significant when controlled for age, gender and initial WBC count employing logistic regression.

\section{Discussion}

Pharmacogenomics is dealing with the fact that the efficacy of the drug depends on the patient's ability to absorb and metabolize the drug, which influences the effectiveness of the treatment. Furthermore, the toxicity of drug depends on the patient's genome. Pharmacogenomics testing is already incorporated as a dosage-calibrating tool in the maintenance phase of childhood ALL treatment in order to minimize the occurrence of serious toxicities during 6-MP treatment. ${ }^{4,32}$

Glucocorticoids are an essential component to induction remission phase of childhood ALL therapy. A poor response to the standard initial GC treatment and the persistence of blast count over 1000 per microliter on the day 8 , puts a patient in a higher risk group with a poor prognosis. The following phases of treatment are dependent on riskdirected stratification of patients. However, many children experience severe toxicity associated with treatment with dangerous side effects, while some of them are not cured..$^{33}$ So, it could be argued that these groupings are not yet comprehensive enough..$^{34}$ As for induction remission phase of ALL treatment, it is essential to find as many potential markers of GC resistance as possible. By analyzing the associations between the pharmacogenetic variants and GC resistance or good response, this study was meant to contribute to individualization of GC treatment, so that the patients could be in future adequately treated according to their genetic background.

A few studies dealt with variants in NR3C1, GSTs and $A B C B 1$ gene in relation with GC toxicity or disease-free survival in childhood ALL patients, often with conflicting results. ${ }^{10,35-38}$ Although toxicity and survival are the most important therapy outcome signifiers, still, they cannot be associated solely with GC response. On the contrary, we believe that GC response on day 8 assessed by blast count in blood is probably the best measure of GC efficacy in childhood ALL, because no other chemotherapeutic drug is given systemically beforehand. Low blast count ( $<100$ blasts/microL) or blast negative status could also be important to reveal patients with particularly good response to
GC therapy. Those patients might require adjustment of GC dose to achieve remission.

In this study we focused on variants in non-coding region of $\mathrm{NR} 3 \mathrm{C} 1$ gene, rather than on the most extensively studied variants of $N R 3 C 1$ gene that were earlier analyzed in regard to GC response on day 8 in childhood ALL. One of those studies found only Bcll variant to be associated with GC response in relatively small Chinese cohort of ALL patients. ${ }^{12}$ However, other studies did not find significant association with GC response on day $8 .{ }^{10,11}$

Concerning the variant rs6198 in the N3RC1 gene, we have found an increased risk of PPR (> 1000 blasts/microL) in the initial stage when the carrier has the rare GG genotype. This variant is important for GR $\beta$ mRNA stabilization. Moreover, the GG genotype leads to greater expression of the GR $\beta$ isoform. ${ }^{17}$ And the increased level of GR $\beta$ isoform leads to the dominant negative inhibition of the GR $\alpha$ isoform. ${ }^{39}$ The GR $\beta$ isoform provides enhanced resistance to the biological and pharmacological effects of glucocorticoids. ${ }^{14,16,40,41}$ The level of isoform GR $\beta$ was shown to influence glucocorticoid response in childhood ALL. Namely, glucocorticoid sensitivity was negatively correlated with GR $\beta / G R \alpha$ ratio in leukemic blast cells. ${ }^{42}$ Our study is the first to report any result concerning association between rs6198 variant and response to GC treatment on day 8 . The association of this variant and glucocorticoid response was shown in patients suffering from other diseases. In the pediatric nephrotic syndrome, it was found that carriers of the GG genotype had a worse treatment outcome, ${ }^{43}$ which is in line with our findings. Also, in the major depressive disorder, a haplotype (rs10482605rs6198) containing the $\mathrm{G}$ allele of rs6198 was associated with GR $\beta$ mRNA stability. This haplotype contributed to the hyperactivity of the hypothalamus-pituitary-adrenal axis. ${ }^{44}$

Our results have shown that carriers of minor NR3C1 rs33389 T allele tended towards higher blast count $(\geq 100$ blasts/microL), while carriers of NR3C1 rs33388 T allele tended towards lower blast count $(<100$ blasts/microL) at day 8 of GC treatment. It has been shown that the variants rs33389 and rs33388, $\mathrm{T}$ and $\mathrm{A}$ alleles respectively, are located in intron 2 of NR3C1, in a region where alternate splicing occurs, resulting in increased expression of isoform GR $\gamma .{ }^{14} \mathrm{GR} \gamma$ has an affinity for the ligand similar to the standard isoform GR $\alpha$, but it lacks the stability of GR $\alpha$ in binding to the glucocorticoid response element. ${ }^{45}$ On the other hand, rs33389 C allele and rs33388 $\mathrm{T}$ allele are 
parts of ACT (rs41423247-rs33389-rs33388) haplotype which is strongly associated with glucocorticoid sensitivity. ${ }^{46}$ Also, in the pediatric nephrotic syndrome, a significant association was shown between this haplotype and a good response to GC treatment. ${ }^{15}$ Moreover, CTA (rs33389-rs33388rs6198) haplotype consisting of alleles found to be favorable for GC response on day 8 in our study, was associated with longer survival time in acute leukemia patients who underwent hematopoietic stem cell transplantation. ${ }^{47}$ Interestingly however, in our cohort, CAA haplotype was associated with PGR. This result further points out favorable association of rs33389 C and rs6198 A alleles with lower blast count.

Carriers of GSTP1 GC (rs1695-rs1138272) haplotype had decreased risk of PPR, were more likely to have low blast count $(<100$ blasts/microL) and to be blast negative on day 8 of GC treatment. It was shown, while investigating the activity and the structure of GSTP1, that this haplotype codes the substrate binding region, H-site, of the GSTP1 protein, turning it into a protein with a much smaller Michaelis constant, leading to less efficient conjugation of agents. ${ }^{20}$ Consequently, glucocorticoid agents are capable of acting for a longer period of time. Our results have also associated GSTP1 rs1138272 T allele carriers and GSTP1 GT haplotype with blast positive status. Two studies that dealt with variants in GSTP1 gene and GC response on day 8 of ALL treatment, did not find significant association, but they enrolled relatively small number of patients. ${ }^{21,48}$

Carriers of the GSTT1 null-genotype were more likely to have higher blast count on day 8 in our childhood ALL cohort. In contrast to our result, one study did not find any association, ${ }^{21}$ while the other observed statistical trend towards a PGR in childhood ALL. ${ }^{48}$ Also, Meissner and coworkers found that in subgroup of childhood ALL patients who were in higher risk for PPR, GSTT1 null allele is correlated with decreased risk of PPR. ${ }^{27}$ When it comes to risk of relapse and outcome in relation with GSTT1 null genotype, conflicting results were noted in two studies that enrolled large number of childhood ALL patients. ${ }^{36,38}$

Regarding $A B C B 1$ gene, we found that carriers of rare CGT (rs1128503-rs2032582-rs1045642) haplotype are more likely to be blast positive. Higher expression of $A B C B 1$ was associated with steroid resistance. ${ }^{25,49}$ Mayor alleles were found to lead to higher $A B C B 1$ expression or higher $\mathrm{ABCB} 1$ activity,$^{50}$ making them more likely to be associated with poor GC response. ${ }^{51}$ Our study is the first to deal with GC response on GC treatment day 8 of childhood ALL patients regarding $A B C B 1$ haplotypes. In a large cohort of idiopathic thrombocytopenic purpura patients, various haplotype combinations of the same variants we analyzed were associated with GC response. ${ }^{51}$ However, no association was found in regard to CGT haplotype.

Despite the promising results, the limitations of the study need to be affirmed. The sample size is not big, since this is a single centric study enrolling patients suffering from a rare disease. Moreover, certain alleles of genetic variants we studied are not frequent, meaning that in some cases there are only a few carriers of certain genotypes. As a consequence, conclusions drawn analyzing such small groups of patients need to be taken with caution. Considering the shortcomings mentioned, it would be of great benefit to validate the results gained in this study on a larger sample preferably using prospective approach.

Association studies on the pharmacogenomic profile of patients and data on the toxicity of drugs are the most promising directions on the road to personalized medicine. The ultimate goal of the ongoing multicentric clinical trials is to optimize the use of known antileukemic drugs in the context of individual pharmacogenomic profile of each patient and molecular markers of the leukemic cells and modulate the treatment resulting in less toxicity and adverse reactions, and a higher survival rates. ${ }^{52}$ Personalized medicine approach of tailoring treatment to the individual characteristics of each patient has been a great success in several diseases. One thing that we have learnt from those successful examples is that a personalized childhood ALL approach implementation may be difficult. Our study pointed out the association between several variants in NR3C1, GSTP1, GSTT1, GSTM1 and $A B C B 1$ genes and GC therapeutic response in the initial phase of remission induction therapy of pediatric ALL patients. We have shown that NR3C1 rs6198 variant and GSTP1 rs1695-rs1138272 haplotype are the most promising pharmacogenetic markers of GC response in ALL patients. However, studies including more childhood ALL patients, as well as more comprehensive analysis of personal "pharmacomics" profiles are needed for discovery of novel potential genetic markers for targeted therapy ${ }^{53}$ and for a design of modulations of the existing treatment protocols, leading to more individualized and more successful childhood ALL treatment. 


\section{Acknowledgement}

This work was supported by Ministry of Education, Science and Technological Development, Republic of Serbia (Grant No. III41004).

\section{References}

1. Schrappe M, Reiter A, Zimmermann M, Harbott J, Ludwig WD, Henze G, et al. Long-term results of four consecutive trials in childhood ALL performed by the ALL-BFM study group from 1981 to 1995 . Leukemia 2000; 14: 220522. doi: 10.1038/sj.leu.2401973

2. Pui C-H, Robison LL, Look AT. Acute lymphoblastic leukaemia. Lancet (London, England) 2008; 371: 1030-43. doi: 10.1016/S0140-6736(08)604572

3. Stary J, Zimmermann M, Campbell M, Castillo L, Dibar E, Donska S, et al. Intensive chemotherapy for childhood acute lymphoblastic leukemia: results of the randomized intercontinental trial ALL IC-BFM 2002. J Clin Oncol 2014; 32: 174-84. doi: 10.1200/JCO.2013.48.6522

4. Rudin S, Marable M, Huang RS. The promise of pharmacogenomics in reducing toxicity during acute lymphoblastic leukemia maintenance treatment. Genomics, Proteomics, Bioinformatics 2017; 15: 82-93. doi: 10.1016/j.gpb.2016.11.003

5. Helmberg A, Auphan N, Caelles C, Karin M. Glucocorticoid-induced apoptosis of human leukemic cells is caused by the repressive function of the glucocorticoid receptor. EMBO J 1995; 14: 452-60.

6. Campbell M. ALL IC-BFM 2009 a randomized trial of the I-BFM-SG for the management of childhood non-B acute lymphoblastic leukemia. 2009; 178.

7. Schmidt S, Rainer J, Ploner C, Presul E, Riml S, Kofler R. Glucocorticoidinduced apoptosis and glucocorticoid resistance: molecular mechanisms and clinical relevance. Cell Death Differ 2004; 11: S45-55. doi: 10.1038/ sj.cdd. 4401456

8. Koper JW, Van Rossum EFC, Van Den Akker ELT. Glucocorticoid receptor polymorphisms and haplotypes and their expression in health and disease. Steroids 2014; 92: 62-73. doi: 10.1016/j.steroids.2014.07.015

9. DeRijk RH, Schaaf M, De Kloet ER. Glucocorticoid receptor variants: clinical implications. J Steroid Biochem Mol Biol 2002; 81: 103-22. doi: 10.1016/ S0960-0760(02)00062-6

10. Eipel OT, Németh K, Török D, Csordás K, Hegyi M, Ponyi A, et al. The glucocorticoid receptor gene polymorphism N363S predisposes to more severe toxic side effects during pediatric acute lymphoblastic leukemia (ALL) therapy. Int J Hematol 2013; 97: 216-22. doi: 10.1007/s12185-012-1236-1

11. Tissing WJE. Genetic variations in the glucocorticoid receptor gene are not related to glucocorticoid resistance in childhood acute lymphoblastic leukemia. Clin Cancer Res 2005; 11: 6050-56. doi: 10.1158/1078-0432. CCR-04-2097

12. Xue L, Li C, Wang Y, Sun W, Ma C, He Y, et al. Single nucleotide polymorphisms in non-coding region of the glucocorticoid receptor gene and prednisone response in childhood acute lymphoblastic leukemia. Leuk Lymphoma 2015; 56: 1704-09. doi: 10.3109/10428194.2014.951848

13. Cartegni L, Chew SL, Krainer AR. Listening to silence and understanding nonsense: Exonic mutations that affect splicing. Nat Rev Genet 2002; 3: 285-98. doi: $10.1038 / \mathrm{nrg} 775$

14. Gross KL, Lu NZ, Cidlowski JA. Molecular mechanisms regulating glucocorticoid sensitivity and resistance. Mol Cell Endocrinol 2009; 300: 7-16. doi: 10.1016/j.mce.2008.10.001.Molecular

15. Zalewski G, Wasilewska A, Zoch-Zwierz W, Chyczewski L. Response to prednisone in relation to NR3C1 intron B polymorphisms in childhood nephrotic syndrome. Pediatr Nephrol 2008; 23: 1073-8. doi: 10.1007/ s00467-008-0772-7

16. Schaaf MJM, Cidlowski JA. Molecular mechanisms of glucocorticoid action and resistance. J Steroid Biochem Mol Biol 2002; 83: 37-48. doi: 10.1016/ S0960-0760(02)00263-7
17. Derijk RH, Schaaf MJ, Turner G, Datson Na, Vreugdenhil E, Cidlowski J, et al. A human glucocorticoid receptor gene variant that increases the stability of the glucocorticoid receptor beta-isoform mRNA is associated with rheumatoid arthritis. J Rheumatol 2001; 28: 2383-8.

18. Vega L. 3. Role of glutathione S-transferase enzymes in toxicology, pharmacology and human disease. Pharmacological and Toxicological Aspects 2010; 661: 45-66.

19. Homma H, Listowsky I. Identification of Yb-glutathione-S-transferase as a major rat liver protein labeled with dexamethasone 21-methanesulfonate. Proc Natl Acad Sci U S A 1985; 82: 7165-69. doi: 10.2307/26329

20. Johansson AS, Stenberg G, Widersten M, Mannervik B. Structure-activity relationships and thermal stability of human glutathione transferase P1-1 governed by the $\mathrm{H}$-site residue 105 . J Mol Biol 1998; 278: 687-98. doi: 10.1006/jmbi.1998.1708

21. Zubowska M, Zielińska E, Zmysłowska A, Bodalski J. [Increased frequency of A-G transition at exon 5 of GSTP1 as a genetic risk factor for acute childhood leukaemia]. [Polish]. Med Wieku Rozwoj 2004; 8: 245-57.

22. Farrell RJ, Menconi MJ, Keates AC, Kelly CP. P-glycoprotein-170 inhibition significantly reduces cortisol and ciclosporin efflux from human intestinal epithelial cells and T lymphocytes. Aliment Pharmacol Ther 2002; 16: 1021 31. doi: 10.1046/j.1365-2036.2002.01238.x

23. Hoffmeyer S, Burk O, von Richter O, Arnold HP, Brockmöller J, Johne A, et al. Functional polymorphisms of the human multidrug-resistance gene: multiple sequence variations and correlation of one allele with P-glycoprotein expression and activity in vivo. Proc Natl Acad Sci U S A 2000; 97: 3473-8. doi: 10.1073/pnas.050585397

24. Ambudkar SV, Dey S, Hrycyna CA, Ramachandra M, Pastan I, Gottesman $\mathrm{MM}$. Biochemical, cellular, and pharmacological aspects of the multidrug transporter. Annu Rev Pharmacol Toxicol 1999; 39: 361-98. doi: 10.1146/ annurev.pharmtox.39.1.361

25. Wasilewska A, Zoch-Zwierz W, Pietruczuk M, Zalewski G. Expression of P-glycoprotein in lymphocytes from children with nephrotic syndrome, depending on their steroid response. Pediatr Nephrol 2006; 21: 1274-80. doi: 10.1007/s00467-006-0187-2

26. Smith LK, Cidlowski JA. Glucocorticoid-induced apoptosis of healthy and malignant lymphocytes. Prog Brain Res 2010; 182: 1-30. doi: 10.1016/ S0079-6123(10)82001-1

27. Meissner B, Stanulla M, Ludwig W-D, Harbott J, Möricke a, Welte K, et al. The GSTT1 deletion polymorphism is associated with initial response to glucocorticoids in childhood acute lymphoblastic leukemia. Leukemia 2004; 18: 1920-3. doi: 10.1038/sj.leu.2403521

28. Vaghela N, Anand IS, Trivedi DH, Jani M. Prognostic value of peripheral blood blast percentage on day 8 in long term cure in patients with ALL. World J Pharmacy Pharm Sci 2014; 3: 1839-47.

29. Chen CL, Liu Q, Relling MV. Simultaneous characterization of glutathione S-transferase $\mathrm{M} 1$ and $\mathrm{T} 1$ polymorphisms by polymerase chain reaction in American whites and blacks. Pharmacogenetics 1996; 6: 187-91.

30. Kurzawski M, Pawlik A, Górnik W, Droździk M. Frequency of common MDR1 gene variants in a Polish population. Pharmacol Rep 2006; 58: 35-40.

31. Excoffier L, Lischer HEL. Arlequin suite ver 3.5: a new series of programs to perform population genetics analyses under Linux and Windows. Mol Ecol Resour 2010; 10: 564-67. doi: 10.1111/j.1755-0998.2010.02847.x

32. Dokmanovic L, Urosevic J, Janic D, Jovanovic N, Petrucev B, Tosic N, et al. Analysis of thiopurine S-methyltransferase polymorphism in the population of Serbia and Montenegro and mercaptopurine therapy tolerance in childhood acute lymphoblastic leukemia. Ther Drug Monit 2006; 28: 800-06. doi: 10.1097/01.ftd.0000249947.17676.92

33. Jackson RK, Irving JAE, Veal GJ. Personalization of dexamethasone therapy in childhood acute lymphoblastic leukaemia. Br J Haematol 2016; 173: 13-24. doi: 10.1111/bjh.13924

34. Asselin BL. The right dose for the right patient. Blood 2012; 119: 1617-8. doi: 10.1182/blood-2011-12-395855

35. Labuda M, Gahier A, Gagné V, Moghrabi A, Sinnett D, Krajinovic M Polymorphisms in glucocorticoid receptor gene and the outcome of childhood acute lymphoblastic leukemia (ALL). Leuk Res 2010; 34: 492-97. doi: 10.1016/j.leukres.2009.08.007 
36. Stanulla $M$, Schrappe $M$, Brechlin AM, Zimmermann $M$, Welte $K$. Polymorphisms within glutathione S-transferase genes (GSTM1, GSTT1, GSTP1) and risk of relapse in childhood B-cell precursor acute lymphoblastic leukemia: a case-control study. Blood 2000; 95: 1222-8.

37. Stanulla M, Schäffeler E, Arens S, Rathmann A, Schrauder A, Welte K, et al. GSTP1 and MDR1 genotypes and central nervous system relapse in childhood acute lymphoblastic leukemia. Int J Hematol 2005; 81: 39-44.

38. Franca R, Rebora P, Basso G, Biondi A, Cazzaniga G, Crovella S, et al. Glutathione S-transferase homozygous deletions and relapse in childhood acute lymphoblastic leukemia: a novel study design in a large Italian AIEOP cohort. Pharmacogenomics 2012; 13: 1905-16. doi: 10.2217/pgs.12.169

39. Longui CA, Vottero A, Adamson PC, Cole DE, Chrousos GP. Low glucocorticoid receptor alpha/beta ratio in T-cell lymphoblastic leukemia. Horm Metab Res 2000; 32: 401-6. doi: 10.1055/s-2007-978661

40. Turner JD, Schote AB, Macedo JA, Pelascini LPL, Muller CP. Tissue specific glucocorticoid receptor expression, a role for alternative first exon usage? Biochem Pharmacol 2006; 72: 1529-37. doi: 10.1016/j.bcp.2006.07.005

41. Bamberger CM, Bamberger AM, De Castro M, Chrousos GP. Glucocorticoid receptor B, a potential endogenous inhibitor of glucocorticoid action in humans. J Clin Invest 1995; 95: 2435-41. doi: 10.1172/JCl117943

42. Koga $Y$, Matsuzaki A, Suminoe A, Hattori $H$, Kanemitsu $S$, Hara T. Differential mRNA expression of glucocorticoid receptor $\alpha$ and $\beta$ is associated with glucocorticoid sensitivity of acute lymphoblastic leukemia in children. Pediatr Blood Cancer 2005; 45: 121-27. doi: 10.1002/pbc.20308

43. Teeninga N, Kist-Van Holthe JE, Van Den Akker ELT, Kersten MC, Boersma $\mathrm{E}, \mathrm{Krabbe} \mathrm{HG}$, et al. Genetic and in vivo determinants of glucocorticoid sensitivity in relation to clinical outcome of childhood nephrotic syndrome. Kidney Int 2014; 85: 1444-53. doi: 10.1038/ki.2013.531

44. Kumsta R, Moser D, Streit F, Koper JW, Meyer J, Wüst S. Characterization of glucocorticoid receptor gene (GR, NR3C1) promoter polymorphism reveals functionality and extends a haplotype with putative clinical relevance. $\mathrm{Am}$ J Med Genet B Neuropsychiatr Genet 2009; 150: 476-82. doi: 10.1002/ ajmg.b.30837

45. Beger C, Gerdes K, Lauten M, Tissing WJE, Fernandez-Munoz I, Schrappe $\mathrm{M}$, et al. Expression and structural analysis of glucocorticoid receptor isoform gamma in human leukaemia cells using an isoform-specific real-time polymerase chain reaction approach. Br J Haematol 2003; 122: 245-52. doi: 10.1046/j.1365-2141.2003.04426.x

46. Stevens A, Ray DW, Zeggini E, John S, Richards HL, Griffiths CEM, et al. Glucocorticoid sensitivity is determined by a specific glucocorticoid receptor haplotype. J Clin Endocrinol Metab 2004; 89: 892-97. doi: 10.1210/ jc. 2003-031235

47. Pearce KF, Balavarca Y, Norden J, Jackson G, Holler E, Dressel R, et al. Impact of genomic risk factors on survival after haematopoietic stem cell transplantation for patients with acute leukaemia. Int J Immunogenet 2016; 43: 404-12. doi: 10.1111/iji.12295

48. Anderer G, Schrappe M, Brechlin AM, Lauten M, Muti P, Welte K, et al. Polymorphisms within glutathione S-transferase genes and initial response to glucocorticoids in childhood acute lymphoblastic leukaemia. Pharmacogenetics 2000; 10: 715-26. doi: 10.1097/00008571-20001100000006

49. Jafar T, Prasad N, Agarwal V, Mahdi A, Gupta A, Sharma RK, et al. MDR-1 gene polymorphisms in steroid-responsive versus steroid-resistant nephrotic syndrome in children. Nephro Dial Transplant 2011; 26: 3968-74. doi: $10.1093 /$ ndt/gfr150

50. Wang $D$, Johnson $A D$, Papp $A C$, Kroetz DL, Sadée W. Multidrug resistance polypeptide 1 (MDR1, ABCB1) variant 3435C>T affects mRNA stability. Pharmacogenet Genomics 2005; 15: 693-704. doi: 10.1097/01. fpc.0000178311.02878.83

51. Xuan M, Li H, Fu R, Yang Y, Zhang D, Zhang X, et al. Association of ABCB1 gene polymorphisms and haplotypes with therapeutic efficacy of glucocorticoids in Chinese patients with immune thrombocytopenia. Hum Immuno 2014; 75: 317-21. doi: 10.1016/j.humimm.2014.01.013

52. Hunger SP, Mullighan CG. Acute lymphoblastic leukemia in children. $N$ Engl J Med 2015; 373: 1541-52. doi: 10.1056/NEJMra1400972

53. Dokmanovic L, Milosevic G, Peric J, Tosic N, Krstovski N, Janic D, et al. Next generation sequencing as a tool for pharmacogenomic profiling: Nine novel potential genetic markers for targeted therapy in childhood acute lymphoblastic leukemia. Srp Arh Celok Lek 2017; 145: 194-94. doi: 10.2298/ SARH171003194D 